\title{
$\beta$-Phenylethylamine Stimulates Striatal Acetylcholine Release through Activation of the AMPA Glutamatergic Pathway
}

\author{
Kota Ishida, Mikio Murata, Masatoshi Kato, Iku Utsunomiya, Keiko Hoshi, and Kyoji Taguchi* \\ Department of Pharmacotherapeutics, Showa Pharmaceutical University; 3-3165 Higashitamagawagakuen, Machida, \\ Tokyo 194-0042, Japan. Received March 8, 2005; accepted June 14, 2005
}

\begin{abstract}
Using an in vivo intra-striatal microdialysis technique, we examined the effects of systemically administered $\beta$-phenylethylamine $(\beta$-PEA), a psychomotor stimulating trace amine, on striatal acetylcholine release in freely moving rats. Infusion of $N$-methyl-D-aspartic acid $\left(\mathrm{NMDA} ; 1^{-5} \mathrm{M}\right)$ significantly increased acetylcholine release. In addition, locally applied amino-3-hydroxy-5-methylisozasole-4-propionic acid (AMPA; $\left.10^{-5} \mathrm{M}\right)$ significantly increased acetylcholine release in the striatum. Intra-striatal application of 6-cyano-7-nitroquinoxaline-2,3-dione $\left(\mathrm{CNQX} ; \mathbf{1 0}^{-5} \mathrm{M}\right)$, an AMPA-type glutamatergic receptor antagonist, had little effect on acetylcholine release, while application of MK-801 $\left(10^{-5} \mathrm{M}, 1^{-6} \mathrm{M}\right)$, an NMDA-type glutamatergic receptor antagonist, significantly reduced acetylcholine release. Acetylcholine within striatal perfusate was significantly increased by intraperitoneal administration of $\beta$-PEA in a dose-dependent manner. This increase in acetylcholine release was completely blocked by application of CNQX $\left(1^{-5} \mathrm{M}\right)$ through the microdialysis probe into the striatum. However, increased acetylcholine response to systemic $\beta$-PEA was unaltered by addition of MK-801 to the perfusion medium. These results suggest a regulatory function of $\beta$-PEA, mediated by AMPA-type glutamatergic receptors, on the release of acetylcholine in the rat striatum.
\end{abstract}

Key words $\beta$-phenylethylamine; acetylcholine; glutamatergic receptor; striatum; in vivo microdialysis

$\beta$-Phenylethylamine ( $\beta$-PEA) is an endogenous trace amine closely related to the classical monoamine transmitters, and is widespread in the central nervous system, including the mesolimbic and caudate-putamen structures of rodents and mammals. ${ }^{1-4)}$ The synthetic and metabolic pathways of $\beta$-PEA are known. Formed by enzymatic decarboxylation of a precursor amino acid, phenylalanine, $\beta$-PEA is metabolized by monoamine oxidase B. ${ }^{5)}$

The psychomotor activity induced by $\beta$-PEA is comparable to that of amphetamine. $\beta$-PEA increases locomotion and induces stereotypic behaviors in rodents and monkeys., ${ }^{4,6,7)}$ Electrophysiological studies demonstrate an inhibitory effect of $\beta$-PEA on dopaminergic neuronal activity. ${ }^{8,9}$ Biochemical studies demonstrate high levels of $\beta$-PEA in the striatum. We previously reported that systemic administration of $\beta$-PEA increases the release of acetylcholine in the striatum of rats using in vivo microdialysis. ${ }^{10)}$ While $\beta$-PEA appears to regulate neuronal function in the striatum, little is known about the effects of $\beta$-PEA on cholinergic and glutamatergic neurons in rat striatum.

The striatum receives extensive glutamatergic projections from both the cortex and thalamus, which have excitatory effects on different striatal functions, including cholinergic activity. ${ }^{11,12)}$ Anatomical studies demonstrate monosynaptic cortical and thalamic inputs to aspiny dendrites of cholinergic interneurons. ${ }^{13,14)}$ Corticostriatal and thalamostriatal pathways might use the excitatory amino acid, glutamate, as the neurotransmitter. ${ }^{15,16)}$ Current evidence suggests that corticostriatal and thalamostriatal nerve terminals are in contact with striatal cholinergic neurons. In addition, activation of glutamatergic receptors by $N$-methyl-D-aspartic acid (NMDA) and amino-3-hydroxy-5-methylisozasole-4-propionic acid (AMPA) using in vivo microdialysis might stimulate the release of acetylcholine in the striatum. ${ }^{17-20)}$ Activation of glutamatergic neurons might thus result in acetylcholine release following exposure to $\beta$-PEA.

The present study investigated whether NMDA- and
AMPA-type glutamatergic receptors might influence the effects of systemic $\beta$-PEA on acetylcholine release in rat striatum.

\section{MATERIALS AND METHODS}

Surgical Procedures Male Wistar rats weighing 270$360 \mathrm{~g}$ (Japan SLC, Shizuoka, Japan) were used in this study. All procedures for animal treatment and surgery were in accordance with the Guidelines for the Care and Use of Laboratory Animals (National Academy of Science, 1997).

Rats $(n=38)$ were anesthetized with pentobarbital-Na $(50 \mathrm{mg} / \mathrm{kg}$, i.p.), and positioned in a stereotaxic apparatus. Guide cannulae were implanted into the upper part of the striatum (bregma: $+0.3 \mathrm{~mm}$, lateral: $3.0 \mathrm{~mm}$, depth: $3.0 \mathrm{~mm}$ ). ${ }^{21)}$ Guide cannulae were held firmly in place by dental acrylic and anchored to the skull using stainless screws. All experiments were performed $7 \mathrm{~d}$ after surgery.

\section{MICRODIALYSIS TECHNIQUE}

Rats were placed in a Plexiglas cage $(30 \mathrm{~cm} \times 30 \mathrm{~cm} \times$ $38 \mathrm{~cm}$ ), and microdialysis probes (dialysis membrane: length $3.0 \mathrm{~mm}$, diameter $0.5 \mathrm{~mm}$, AF-03, Eicom Co., Japan) were inserted into the striatum through previously implanted guide cannulae. Each probe was connected to polyethylene inflow and outflow tubes in addition to a microsyringe pump and perfusate collection vial. Perfusion solution $(125 \mathrm{~mm} \mathrm{NaCl}$, $3 \mathrm{~mm} \mathrm{KCl}, 1.3 \mathrm{~mm} \mathrm{CaCl}_{2}, 1 \mathrm{~mm} \mathrm{MgCl}_{2}$, and $23 \mathrm{~mm} \mathrm{NaHCO}_{3}$, in aqueous potassium phosphate buffer $(1 \mathrm{~mm}, \mathrm{pH} 7.4)$ containing neostigmine $(20 \mathrm{~nm})$ was perfused into each dialysis probe at a rate of $2 \mu \mathrm{l} / \mathrm{min}$ and perfusate was collected every 15 min. $^{22)}$ Quantification of acetylcholine within each perfusate sample was performed using high-performance liquid chromatography with electrochemical detection (HPLCECD), as described elsewhere. ${ }^{10)}$ The mobile phase comprised $0.05 \mathrm{M}$ phosphate buffer ( $\mathrm{pH} 8.2$ ) containing $300 \mathrm{mg} / \mathrm{l}$ 
sodium 1-decanesulfonate and $5 \mathrm{mg} / 1$ EDTA-2Na. The detection limit for acetylcholine was appropriately $25 \mathrm{fmol} / 30 \mu \mathrm{l}$.

Data Evaluation Data are presented as mean percentage \pm S.E.M. of baseline acetylcholine levels for each rat prior to drug application. Statistical significance was analyzed by repeated measures one- or two-way analysis of variance (RM-ANOVA), followed by the unpaired $t$-test or Dunnett's multiple comparison test. Maximal changes in acetylcholine release with treatment were analyzed using the paired $t$-test. Differences were considered significant at values of $p<0.05$.

Materials $\beta$-Phenylethylamine hydrochloride was purchased from Tokyo Chemical Industry Co. (Tokyo, Japan). The $\beta$-PEA was dissolved in physiological saline for intraperitoneal administration. NMDA, AMPA, (+)-MK-801 hydrogen maleate and 6-cyano-7-nitroquinoxaline-2,3-dione (CNQX) were purchased from RBI (Natick, Mass., U.S.A.). These drugs were dissolved in perfusion solution for intrastriatal application through dialysis probes. Analytical grade chemicals for the perfusion solution and mobile phase were purchased from Wako Pure Chemical Industries (Osaka, Japan).

\section{RESULTS}

Effect of Intraperitoneal Administration of $\beta$-PEA and Ionotropic Glutamate Receptor Agonists on Striatal Acetylcholine Release Samples of perfusate containing $20 \mathrm{~nm}$ neostigmine were collected every $15 \mathrm{~min}$ and contained a mean of $239.8 \pm 37.6 \mathrm{fmol} / 30 \mu \mathrm{l}(n=38)$ of acetylcholine.

Intraperitoneal administration of $\beta$-PEA caused a dose-dependent increase in acetylcholine release in the striatum. At doses of $12.5 \mathrm{mg} / \mathrm{kg}$ and $25.0 \mathrm{mg} / \mathrm{kg}, \beta$-PEA caused a significant increase in acetylcholine release $(39.9 \pm 13.4 \%$ at $30 \mathrm{~min}, 70.5 \pm 15.3 \%$ at $15 \mathrm{~min}$ ) following administration (two-way RM-ANOVA: treatment-time interaction, $F(20,99)=$ $1.85, p=0.024$, Fig 1A). Acetylcholine levels returned to baseline level within 60 min after systemic $\beta$-PEA administration (Fig. 1A). Maximal increases of $51.2 \pm 6.9 \%(p=$ $0.004)$ and $73.2 \pm 12.7 \%(p<0.001)$ were observed following administration of $12.5 \mathrm{mg} / \mathrm{kg}$ and $25.0 \mathrm{mg} / \mathrm{kg}$ of $\beta$-PEA, respectively (Fig. 1B). These data are consistent with previous report. ${ }^{10)}$

Two ionotropic glutamate receptor agonists, NMDA and AMPA, were perfused into the striatum (Fig. 1C). NMDA $\left(10^{-5} \mathrm{M}\right)$ increased acetylcholine release by a maximum of $50.2 \pm 10.6 \%(p=0.039, n=5)$. AMPA $\left(10^{-5} \mathrm{M}\right)$ significantly increased acetylcholine release by a maximum of $26.7 \pm$ $2.2 \%(p=0.018, n=4$, Fig. $1 \mathrm{C})$.

Effects of Ionotropic Glutamate Receptor Antagonists on Striatal Acetylcholine Release CNQX $\left(10^{-5} \mathrm{M}\right)$ and MK-801 $\left(10^{-6} \mathrm{M}, 10^{-5} \mathrm{M}\right)$ were perfused into striatum through the dialysis probe (Fig. 2). Acetylcholine release within the striatum was unaffected by local administration of CNQX (one-way RM-ANOVA: $F(10,30)=0.61, p=0.795, n=4$ ). However, intra-striatal application of MK-801 $\left(10^{-5} \mathrm{M}\right.$, $\left.10^{-6} \mathrm{M}\right)$, significantly decreased acetylcholine release in a concentration-dependent fashion (one-way RM-ANOVA: $10^{-6} \mathrm{M}, F(10,30)=2.72, p=0.017, n=4 ; 10^{-5} \mathrm{M}, F(10,30)=$ 3.89, $p=0.002, n=4)$. Acetylcholine levels recovered to baseline levels after the removal of MK-801 from perfusate
(A)

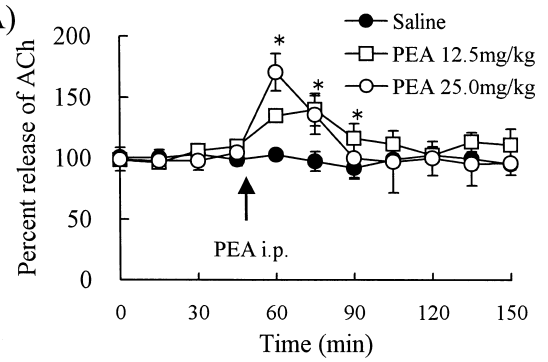

(B)

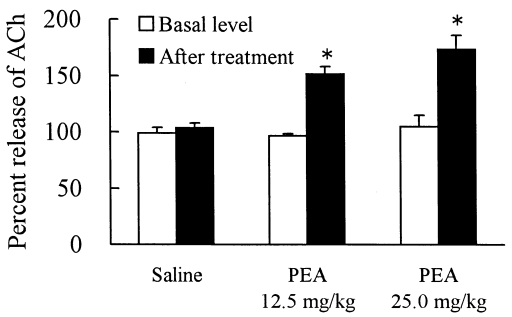

(C)

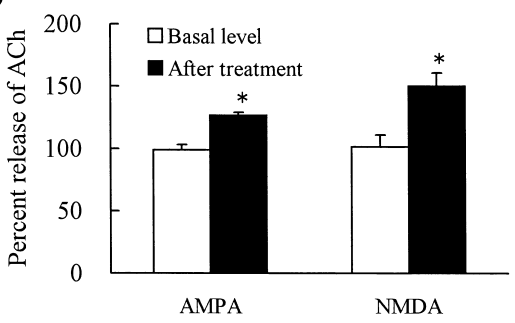

Fig. 1. Effect of Intraperitoneal Administration of $\beta$-PEA on the Release of Acetylcholine in Rat Striatum

(A) $\beta$-PEA was administered at doses of 12.5 and $25.0 \mathrm{mg} / \mathrm{kg}$. Two-way RMANOVA revealed a significant interaction between treatment and time to increase of acetylcholine levels $(F(20,99)=1.85, p=0.024, n=4)$. Asterisks indicate statistical significance $v s$. the saline treated group by Dunnett's multiple comparison test. (B) Data regarding $\beta$-PEA-induced increases in acetylcholine were transformed into data points indicating a maximum increase in acetylcholine levels within the dialysis samples within $60 \mathrm{~min}$. (C) Effect of ionotropic glutamate receptor agonists on the release of acetylcholine in the rat striatum. NMDA $\left(10^{-5} \mathrm{M}\right)$ - and AMPA $\left(10^{-5} \mathrm{M}\right)$-induced increases in acetylcholine were transformed into data points indicating a maximum increase in acetylcholine levels within $60 \mathrm{~min}$. Asterisks indicate significant differences $(p<0.05)$, compared to baseline values.

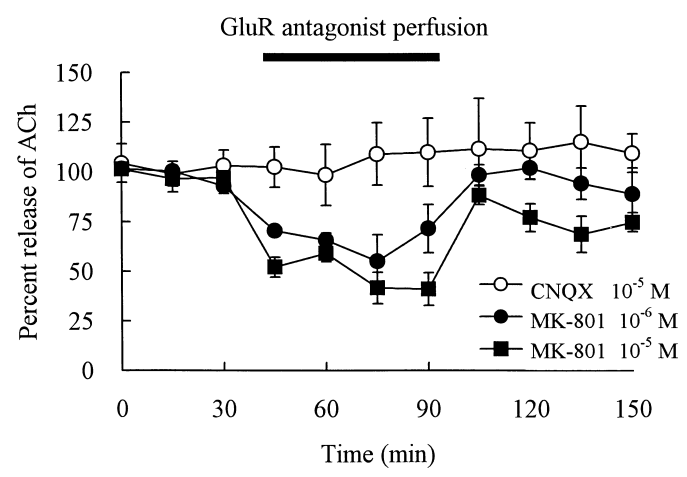

Fig. 2. Effects of Glutamate Receptor Antagonists on Acetylcholine Release in Rat Striatum

CNQX, an AMPA-type receptor antagonist, and MK-801, an NMDA-type receptor antagonist, were applied into the striatum via a microdialysis probe. One-way RMANOVA revealed significant decreases in acetylcholine release following exposure to NMDA $\left(10^{-6} \mathrm{M}, F(10,30)=2.72, p=0.017, n=4 ; 10^{-5} \mathrm{M}, F(10,30)=3.89, p=0.002\right.$, $n=4)$. No significant effect of intra-striatal application of CNQX was observed (oneway RM-ANOVA, $F(10,30)=0.61, p=0.795, n=4)$.

(Fig. 2).

Effects of Glutamate Receptor Antagonists on Systemic $\boldsymbol{\beta}$-PEA-Induced Striatal Acetylcholine Release To inves- 


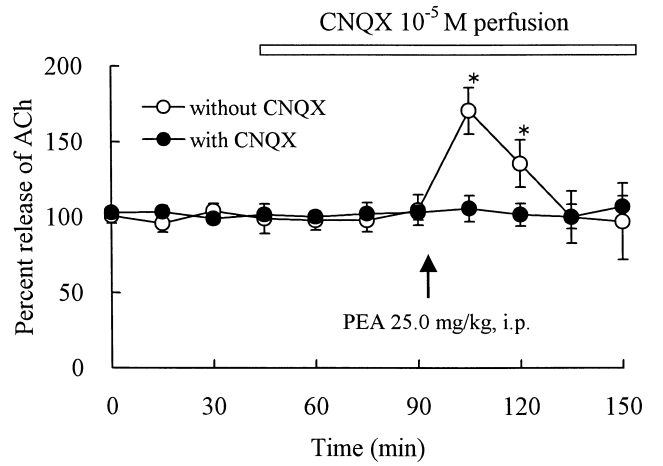

Fig. 3. Effect of the AMPA-Type Glutamate Receptor Antagonist CNQX $\left(10^{-5} \mathrm{M}\right)$ on Systemic $\beta$-PEA $(25.0 \mathrm{mg} / \mathrm{kg}$, i.p.)-Induced Acetylcholine Release

One-way RM-ANOVA revealed no significant effect of $\beta$-PEA on acetylcholine release $(F(10,60)=0.18, p=0.996, n=7)$. Asterisks indicate statistical differences between CNQX and no CNQX treatment by Dunnett's multiple comparison test $(p<0.05)$.

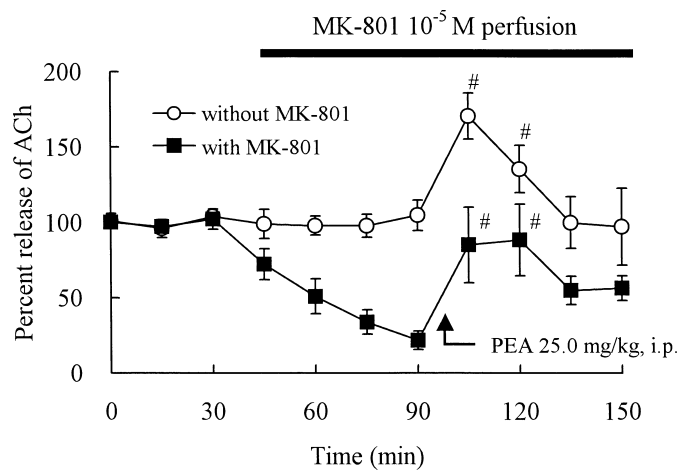

Fig. 4. Effect of the NMDA-Type Glutamate Receptor Antagonist MK$801\left(10^{-5} \mathrm{M}\right)$ on Systemic $\beta$-PEA $(25.0 \mathrm{mg} / \mathrm{kg}$, i.p. $)$-Induced Acetylcholine Release

MK-801 was applied into the striatum via a microdialysis probe, after which increased acetylcholine release was observed following intraperitoneal administration of $\beta$-PEA. Sharps indicate statistical significance $v s$. levels prior to $\beta$-PEA administration by Dunnett's multiple comparison test $(p<0.05)$.

tigate the role of ionotropic glutamate receptors on $\beta$-PEAinduced acetylcholine release in rats, CNQX $\left(10^{-5} \mathrm{M}\right)$ and MK-801 $\left(10^{-5} \mathrm{M}\right)$ were perfused into striatum prior to $\beta$-PEA administration. Systemic $\beta$-PEA-induced increases in acetylcholine were completely blocked by local application of CNQX into the striatum. In other words, systemic $\beta$-PEA no longer stimulated striatal acetylcholine release (one-way RM-ANOVA: $F(10,60)=0.18, p=0.996, n=7$, Fig. 3). However, perfusion of MK-801 into striatum failed to antagonize the effects of systemic $\beta$-PEA administration on acetylcholine release. Significant increases in acetylcholine release were thus observed following intraperitoneal administration of $\beta$-PEA, despite prior administration of MK-801 into the striatum (one-way RM-ANOVA: $F(10,40)=4.46, p<0.001$, $n=5$, Fig. 4).

\section{DISCUSSION}

The present study showed that local perfusion of both an NMDA-type receptor agonist and an AMPA-type receptor agonist into striatum significantly increased spontaneous acetylcholine release. Genetic and histochemical studies have revealed the localization of both NMDA and AMPA recep- tors on cholinergic neurons in rat striatum..$^{23,24)}$ The present study demonstrated the stimulatory function of ionotropic glutamatergic receptors on the release of acetylcholine in the striatum. Although NMDA receptor activation clearly stimulates acetylcholine release, ${ }^{19,20)}$ the effect of AMPA receptor activation has been controversial. ${ }^{17,25)}$ The stimulatory effects of AMPA on the release of acetylcholine have been demonstrated using striatal slices from rats. ${ }^{26-28)}$ The results of previous studies, however, have suggested a weak stimulatory effect of AMPA on $\left[{ }^{3} \mathrm{H}\right]$-acetylcholine release, compared to that of NMDA, using striatal slices from rats in vitro. ${ }^{28,29)}$ Our in vivo microdialysis study with a sensitive quantifiable HPLC system could demonstrate a significant AMPA-induced increase in acetylcholine release. In addition to NMDA receptor, AMPA receptors also seem to play a stimulatory role in acetylcholine release in rat striatum.

While the AMPA receptor antagonist CNQX did not alter the release of acetylcholine, NMDA antagonist MK-801 significantly attenuated acetylcholine release in striatum. Previous studies have likewise demonstrated that perfusion of MK-801 into striatum decreases acetylcholine release. ${ }^{19,30)}$ Our results suggest a tonic control of acetylcholine release in the striatum due to NMDA receptor-mediated glutamatergic activity, rather than AMPA receptor-mediated activity. Consolo et al. ${ }^{18)}$ found that the cerebral cortex increased cholinergic activity in the striatum due to activation of AMPA-type glutamatergic receptors, while the parafascicular thalamic nucleus increased cholinergic activity due to tonic activation of NMDA-type glutamatergic receptors. Parafascicular-striatal glutamatergic projections thus predominantly maintain acetylcholine release, since NMDA receptor antagonist was observed to decrease basal acetylcholine levels during in vivo microdialysis.

We next investigated the effects of ionotropic glutamate receptor antagonists on systemically administered $\beta$-PEA-induced acetylcholine release in the striatum. Systemically administered $\beta$-PEA increased striatal acetylcholine release as previously reported. ${ }^{10)}$ This increase in acetylcholine release in response to systemic $\beta$-PEA was blocked by perfusion of the AMPA receptor antagonist CNQX into the striatum. In contrast, the $\beta$-PEA-induced increase in acetylcholine release was unaffected by local application of the NMDA receptor antagonist $\mathrm{MK}-801$. These results confirm the role of the AMPA-type glutamatergic receptor in generating acetylcholine release in response to systemic $\beta$-PEA.

Biochemical studies have demonstrated the existence of specific binding site for $\beta$-PEA in homogenate of rat forebrain. ${ }^{31)}$ Borowsky et al. ${ }^{32)}$ and Bunzow et al. ${ }^{33)}$ identified 15 mammalian receptors specific for trace amines. These receptors each possess 7 transmembrane regions and are coupled to $\mathrm{G}$ proteins. TA 1 and TA 2 receptors are found as specific receptor for $\beta$-PEA. A widespread distribution of TA1 receptor has also been revealed in the central nervous system by in situ hybridization histochemistry. ${ }^{32)}$

Electrophysiological studies have shown that microiontophoretic application of $\beta$-PEA acts post-synaptically to potentiate cortical neuron response to iontophoretically applied norepinephrine. ${ }^{34)}$ Conversely, dopamine neurons in the rat substantia nigra pars compacta are inhibited by systemic administration of $\beta$-PEA, ${ }^{8)}$ while $\beta$-PEA stimulates the release of dopamine in the striatum. ${ }^{35,36}$ These lines of evi- 
dence suggest the localization of TA1 and/or TA2 receptors on neurons in cerebral cortex, substantia nigra and striatum.

We have previously demonstrated the decreasing release of acetylcholine induced by local application of $\beta$-PEA into the striatum, and the lack of effect following local application of $\mathrm{D}_{1}$ or $\mathrm{D}_{2}$ dopamine receptor antagonists on $\beta$-PEA-induced release of acetylcholine in the striatum using in vivo microdialysis. $^{10)}$ Increased release of acetylcholine after systemic administration of $\beta$-PEA might thus be primarily regulated by neural mechanisms of extra-striatal origin, rather than modulation of the nigrastriatal dopaminergic system.

Striatal cholinergic neurons are innervated from at least 2 distinct glutamatergic pathways from parafascicular thalamic nucleus or cerebral cortex. NMDA receptor and AMPA receptor are differentially involved in striatal acetylcholine release. ${ }^{18)}$ The present study demonstrated the close involvement of AMPA receptor in the stimulated release of acetylcholine induced by systemic $\beta$-PEA administration. Systemic administration of $\beta$-PEA is thus likely to stimulate neuronal activity within the cerebral cortex via the activation of TA1 and/or TA 2 receptors, thereby enhancing corticostriatal glutamatergic activity, resulting in striatal acetylcholine release via the activation of AMPA receptors on striatal cholinergic neurons.

Based on the results of these in vivo microdialysis studies in freely moving rats, systemic administration of $\beta$-PEA stimulates the release of acetylcholine in the striatum via the activation of AMPA glutamatergic receptors. In other words, these findings lead to the conclusion that acetylcholine release in the striatum is regulated by AMPA glutamatergic neurons that are affected by $\beta$-PEA in extra-striatal site (predominantly the cerebral cortex).

Acknowledgements The authors gratefully acknowledge Mr. K. Takahashi for his excellent technical assistance.

\section{REFERENCES}

1) Durden D. A., Phillips S. R., Boulton A. A., Can. J. Biochem., 51, 995-1002 (1973).

2) Philips S. R., Rozdilsky B., Boulton A. A., Biol. Psychiatry, 13, 5157 (1978).

3) Reynolds G. P., Sandler M., Hardy J., Bradford H., J. Neurochem., 34, 1123-1125 (1980).

4) Paterson I. A., Juorio A. V., Boulton A. A., J. Neurochem., 55, $1827-$ 1837 (1990).

5) Yang H. Y., Neff N. H., J. Pharmacol. Exp. Ther., 187, 365-371 (1973).

6) Tinklenberg J. R., Gillin J. C., Murphy G. M., Staub R., Wyatt R. J.,
Am. J. Psychiatry, 135, 576-578 (1978).

7) Dourish C. T., Pharmacol. Biochem. Behav., 22, 159-162 (1985).

8) Barroso N., Rodriguez M., Eur. J. Pharmacol., 297, 195-203 (1996).

9) Geracitano R., Federici M., Prisco S., Bernardi G., Mercuri N. B., Neuropharmacol., 46, 807-814 (2004).

10) Kato M., Ishida K., Chuma T., Abe K., Shigenaga T., Taguchi K., Miyatake T., Eur. J. Pharmacol., 418, 65-71 (2001).

11) Graybiel A. M., Trends Neurol. Sci., 13, 244-254 (1990).

12) Schmidt W. J., J. Neural. Transm., 46, 67-76 (1995).

13) Snell L. D., Johnson K. M., J. Pharmacol. Exp. Ther, 238, 938-946 (1986).

14) Lapper S. R., Bolam J. P., Neuroscience, 51, 533-545 (1992).

15) Spencer H. J., Brain Res., 102, 91-101 (1976).

16) Wilson C. J., Chang J. T., Kitai S. T., Exp. Brain Res., 51, 217-226 (1983).

17) Anderson J. J., Kuo S., Chase T. N., Neurosci. Lett., 176, 264-268 (1994).

18) Consolo S., Baldi G., Giorgi S., Nannini L., Eur. J. Neurosci., 8, 2702-2710 (1996).

19) Ikarashi Y., Yuzurihara M., Takahashi A., Ishimaru H., Shiobara T., Maruyama Y., Brain Res., 795, 215-220 (1998).

20) Knauber J., Kischka U., Roth M., Schmidt W. J., Hennerici M., Fassbender K., J. Neural. Trans., 106, 35-45 (1999).

21) Paxinos G., Watson C., "The Rat Brain in Stereotaxic Coordinates," 2nd ed., Academic Press, London, 1986.

22) Acquas E., Wilson C., Fibiger H. C., J. Pharmacol. Exp. Ther., 281, $360-368$ (1997)

23) Kuppenbender K. D., Albers D. S., Iadarola M. J., Landwehrmeter G. B., Standaert D. G., J. Comp. Neurol., 415, 204-217 (1999).

24) Chan W. S., Yeung C. W., Chung E. K., Law W. K., Chan Y. S., Yung K. K., Neurosignals, 12, 302-309 (2003).

25) Giovannini M. G., Camilli F., Mundula A., Bianchi L., Colivicchi A., Pepeu G., Neuroscience, 65, 409-415 (1995).

26) Jin S., Fredholm B. B., Neuropharmacology, 33, 1039-1048 (1994).

27) Jin S., Neuropharmacology, 33, 1503-1510 (1997).

28) Arruda Paes P. C., Magalhaes L., Camillo M. A. P., Rogero J. R., Troncone L. R. P., Neurosci. Res., 49, 289-295 (2004).

29) Hanania T., Johnson K. M., Brain Res., 844, 106-117 (1999).

30) Damsma G., Robertson G. S., Chui-se T., Fibiger H. C., J. Pharmacol. Exp. Ther., 259, 1064-1072 (1991).

31) Hauger R. L., Skolnick P., Paul S. M., Eur. J Pharmacol., 83, 147148 (1982).

32) Borowsky B., Adham N., Jones K. A., Raddatz R., Artymyshyn R., Ogozalek K. L., Durkin M. M., Lakhlani P. P., Bonini J. A., Pathirana S., Boyle N., Pu X., Kouranova E., Lichtblau H., Ochoa F. Y., Branchek T. A., Gerald C., Proc. Natl. Acad. Sci. U.S.A., 98, 89668971 (2001).

33) Bunzow J. R., Sonders M. S., Arttamangkul S., Harrison L. M., Zhang G., Quigley D. I., Darland T., Suchland K. L., Pasumamula S., Kennedy J. L., Olson S. B., Magenis R. E., Amara S. G., Grandy D. K.. Mol. Pharmacol., 60, 1181-1188 (2001).

34) Paterson I. A., Boulton A. A., Brain Res. Bull., 20, 173-177 (1988).

35) Dyck L. E., Yang C. R., Boulton A. A., J. Neurochem. Res., 10, $211-$ 220 (1983).

33) Bailey B. A., Phillips S. R., Boulton A. A., Neurochem. Res., 12, $173-178$ (1987). 